\title{
Disparities in Breast Cancer and African Ancestry: A Global Perspective
}

\author{
Lisa A. Newman, MD, MPH, FACS, FASCO \\ Department of Surgery, Breast Care Center, University of Michigan Comprehensive Cancer Center, \\ Ann Arbor, Michigan
}

- Abstract: Recognition of breast cancer disparities between African-American and White American women has generated exciting research opportunities investigating the biologic and hereditary factors that contribute to the observed outcome differences, leading to international studies of breast cancer in Africa. The study of breast cancer in women with African ancestry has opened the door to unique investigations regarding breast cancer subtypes and the genetics of this disease. International research efforts can advance our understanding of race/ethnicity-associated breast cancer disparities within the USA; the pathogenesis of triple negative breast cancer; and hereditary susceptibility for breast cancer.

Key Words: African-American, African ancestry, breast cancer disparities, breast cancer subtypes, triple negative breast cancer

A dvances in travel and communication technology have prompted repeated observations that the world seems to be getting smaller. Individuals and communities separated by oceans and/or thousands of miles can share audiovisual as well as live interactions on a regular basis. These developments have affected what we know about breast cancer and its disparate impact on population subsets. The impact of breast cancer on African-American (AA) compared to White American/Caucasian (WA) women is characterized by complex and seemingly paradoxical differences, with lifetime incidence rates being lower despite higher mortality rates. International research efforts have enlightened us regarding the breast cancer burden of Africa, and it now appears that African ancestry is associated with inherited susceptibility for specific patterns of disease. AA and sub-Saharan Africans have shared ancestry as a consequence of the colonial-era slave trade and African diaspora. This has resulted in acknowledgement of hereditary contributions to the multifactorial explanations for similarities in the breast cancer burden of Africa and AA (1). Differences in breast cancer incidence/outcome between AA

Address correspondence and reprint requests to: Lisa A. Newman, MD, MPH, FACS, FASCO, Professor of Surgery, Director, Breast Care Center, University of Michigan Comprehensive Cancer Center, 1500 East Medical Center Drive, Ann Arbor, MI 48109, USA, or e-mail: lanewman@umich.edu

DOI: $10.1111 /$ tbj.12369

(C) 2015 Wiley Periodicals, Inc., 1075-122X/15

The Breast Journal, Volume 21 Number 2, 2015 133-139 and WA have historically been ascribed to socioeconomic disadvantages, but recent studies of breast cancer subtypes as well as correlations between triple negative breast cancer (TNBC), hereditary susceptibility genetic mutations, and African ancestry have strengthened our understanding of race/ethnicity-associated disparities. This review will summarize the currently available information on breast cancer disparities related to racial-ethnic identity, taking ancestral hereditary factors into account.

\section{BREAST CANCER INCIDENCE AND AFRICAN ANCESTRY}

Population-based incidence rates for breast cancer are lower in AA compared to WA women and breast cancer appears to be a low-incidence disease in the continent of Africa. As shown in Figure 1, the lower lifetime incidence rates for breast cancer among AA compared to WA women have been documented by the Surveillance, Epidemiology and End Results (SEER) Program since its inception several decades ago. SEER also documents a poorly understood crossover in breast cancer age-incidence rates (2). Up to the age of 45 years, population based incidence rates of breast cancer are higher for AA compared to WA women; furthermore, the average age at breast cancer diagnosis is 62 years for WA compared to only 57 for AA patients (3). While accurate population-based 
tumor registry data in low- and middle-income countries (LMIC) are sparse, the existing data suggest that breast cancer is a low-incidence disease in Africa (4). Breast cancer patients in Africa also tend to be younger than those in Europe and North America, with an average age of $45-48$ years $(1,5)$, although this younger age distribution clearly reflects the unfortunately shorter life expectancy for populations in LIMC. A final breast cancer incidence pattern of note is related to gender. Population-based incidence rates of male breast cancer are higher among AA compared to WA, and the frequency of male breast cancer also appears to be increased for Africans compared to Europeans $(4,6)$.

\section{BREAST CANCER MORTALITY AND AFRICAN ANCESTRY}

Figure 1 also demonstrates the higher breast cancer mortality rates that are observed for AA compared to WA. These population-based mortality differences did not emerge until nearly 1980, at which point they begin to decrease for WA but remain mostly unchanged for AA. Since tamoxifen as endocrine therapy for breast cancer became available in the late 1970s, this pattern likely reflects the fact that fewer AA breast cancer patients have hormone receptorpositive disease (discussed below). The mortality differences are present in every age category. Figure 2
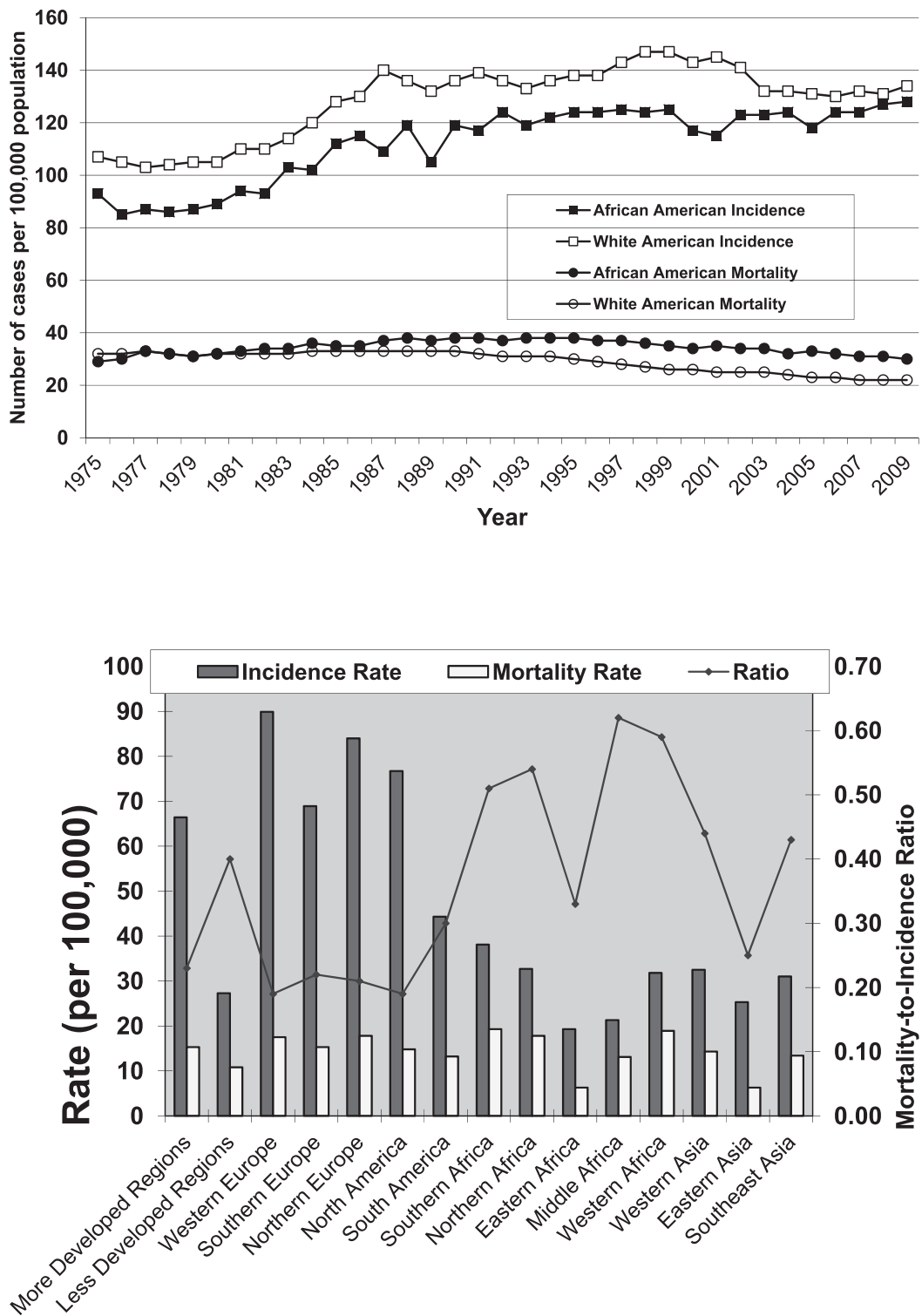

Figure 1. Population-based breast cancer incidence and mortality rates in $\mathrm{AA}$ and White American women, from the Surveillance, Epidemiology, and End Results program (48). Note that disparities in mortality curves do not become apparent until mid1980s, following availability and adoption of tamoxifen as systemic therapy for breast cancer.
Figure 2. International variation in breast cancer incidence, mortality, and mortality-toincidence ratios from Newman (3), Jemal et al. (49) and Globocan 2008 (50). 
demonstrates the fact that although breast cancer incidence and mortality are both lower in LMIC compared to more affluent countries, the mortalityto-incidence ratios are dramatically higher in socioeconomically disadvantaged populations.

\section{BREAST CANCER PRESENTATION, SUBTYPES, AND AFRICAN ANCESTRY}

The earliest detectable form of breast cancer is the ductal carcinoma in situ (DCIS) lesion, which is most commonly detected as a mammographic abnormality. This pre-invasive disease is associated with $98 \%$ survival rates, and in the discussion of whether African ancestry is associated with biologically unfavorable patterns of breast cancer progression, it is reasonable to compare outcomes for AA versus WA DCIS patients. No significant data exist regarding DCIS patterns in Africa because of the absence of populationbased mammography screening programs.

Several studies-some population-based, others from single institutions - have revealed varying degrees and patterns of treatment failure for DCIS related to racial/ethnic identity. The largest (7) is a pooled analysis of studies conducted internationally on DCIS outcomes. This robust composite study demonstrated worse local and distant survival outcomes for AA patients. The included SEER-based pooled analyses revealed a $35 \%$ higher overall mortality for AA compared to WA $(\mathrm{RR}=1.35 ; 95 \%$ confidence interval 1.12-1.62). Risk of invasive and advanced recurrences were increased for AA patients.

A SEER analysis by Li et al. (8) evaluated incidence rates of invasive cancer among patients with a prior history of DCIS. AA women had more than twice the risk of being diagnosed with subsequent Stage III/IV breast cancer compared to WA. Similarly, the California Cancer Registry reported a nearly two-fold higher relative risk of invasive ipsilateral breast cancer among AA women previously treated for DCIS (9). AA DCIS patients had a 1.6 relative risk $(95 \%$ confidence interval 1.1-2.1) of local recurrence after breast-conserving surgery among nearly three thousand women treated in the Cancer Research Network, a consortium of 14 integrated health care delivery systems (10). The M.D. Anderson Cancer Center (MDACC) $(11,12)$ and the Henry Ford Health System (13) have both reported DCIS outcomes related to racial/ethnic identity. The two studies from MDACC had seemingly contrasting results. In their retrospective analysis of nearly two thousand DCIS patients (74\% WA; 11\% AA; 9\% Hispanic; and 5\% Asian/Pacific Islander) with 4.8 years median follow-up, there were no race/ethnicity-related outcome differences, but the Hispanic patients tended to be younger than the AA and WA patients (11). However, a separate analysis looked at 25 patients experiencing distant metastatic disease among 2,123 cases of pure DCIS (frequency of distant metastasis $0.14 \%)$. Interestingly, AA accounted for $24 \%$ of the patients with metastatic disease, despite accounting for only $11.5 \%$ of the total DCIS population (12).

Stark et al. (13) evaluated the diverse cohort of 336 DCIS cases (30\% AA) from the Henry Ford Health System in Detroit, Michigan. With a mean follow-up time of nearly 5 years, the risk of ipsilateral second cancers was 3.96 for the AA patients ( $95 \%$ confidence interval $1.42-11.04 ; p=0.01$ ), but the risk of contralateral new breast cancers was similar for both groups.

As noted above, disparities in breast cancer mortality rates between AA and WA became apparent approximately 30 years ago, following the advent of tamoxifen as adjuvant therapy for breast cancer. Once hormone receptor testing became standard, differences in breast cancer patterns were documented, with AA women having an approximately two-fold higher frequency of hormone receptor negative disease compared to WA women. Routine immunohistochemistry for evaluation of HER2/neu over the past 10 years has led to extensive research regarding tumors that are negative for the estrogen receptor, the progesterone receptor, and HER2/neu, commonly referred-to as TNBC. The TNBC phenotype accounts for $15 \%$ of WA breast cancer patients compared to approximately $30 \%$ of the tumors in AA. TNBC tends to be a more challenging pattern of disease because it is not amenable to therapy with targeted systemic treatments, and also because the majority belongs to the inherently aggressive basal breast cancer subtype as defined by gene expression studies (14-17).

International studies have furthermore revealed that breast cancer patients from sub-Saharan Africa have some of the highest frequencies of TNBC compared to any other populations in the world. Table 1 summarizes studies reporting frequencies of TNBC among various population subsets within the USA and internationally. Interestingly, data from the population-based California Cancer Registry have also demonstrated higher frequencies of TNBC among AA men with breast cancer compared to WA men with breast cancer (18). 
Table 1. Frequency of Triple Negative Breast Cancer in Various Countries and Population Subsets

\begin{tabular}{|c|c|c|}
\hline Country & Study & TNBC (\%) \\
\hline Kenya & Trinkaus et al. 2011 (54) & 32 \\
\hline Uganda & Roy and Othieno 2011 (55) & 36 \\
\hline Ghana & Stark et al. 2010 (5) & 82 \\
\hline Kenya & Bird et al. 2008 (56) & 44 \\
\hline Sudan & Awadelkarim 2011 & 16 \\
\hline Tunisia & Abdelkrim 2010 & 18 \\
\hline India & Ambroise 2011 & 25 \\
\hline Malaysia & Teoh 2011 & 15 \\
\hline Malaysia & Tan 2009 & 18 \\
\hline India & Ghosh 2011 & 29 \\
\hline Indonesia & $\mathrm{Ng} 2011$ & 21 \\
\hline Canada & Dent et al. 2007 (57) & 11 \\
\hline Turkey & Turkoz et al. 2013 (58) & 12 \\
\hline Greece & Fostira et al. 2012 (59) & 8 \\
\hline China & Song et al. 2013 (60) & 22 \\
\hline \multirow[t]{5}{*}{ USA } & Carey et al. 2006 (61) & $\begin{array}{l}\text { AA (premenopausal): } 39 \\
\text { WA: } 16\end{array}$ \\
\hline & Morris et al. 2007 (62) & $\begin{array}{l}\text { AA: } 21 \\
\text { WA: } 10\end{array}$ \\
\hline & Lund et al. 2009 (63) & $\begin{array}{l}\text { AA: } 47 \\
\text { WA: } 22\end{array}$ \\
\hline & Moran et al. 2008 (64) & $\begin{array}{l}\text { AA: } 21 \\
\text { WA: } 8\end{array}$ \\
\hline & Chavez-Macgregor et al. 2013 (18) & $\begin{array}{l}\text { AA Males: } 9 \\
\text { WA Males: } 3\end{array}$ \\
\hline
\end{tabular}

Recent epidemiologic research reveals that clinical and reproductive risk factors differ for TNBC versus non-TNBC. Multiparity, for example, has long been accepted as protecting against breast cancer development, but subset analyses show that multiple pregnancies only reduce the risk of hormone receptor-positive/ non-TNBC (19-24). Several of these studies show that multiparity increases likelihood of being diagnosed with TNBC $(19,21,23,24)$. The association between childbearing patterns and TNBC prompts speculation that multiparity might account for the increased burden of TNBC observed in sub-Saharan Africa, since women in LMIC tend to start childbearing at relatively young ages and they tend to have multiple pregnancies. It is noteworthy however that as shown in Table 1, frequencies of TNBC are nonetheless higher in sub-Saharan Africa compared to other LMIC in Asia and northern Africa, where the child-bearing patterns are likely to be similar.

\section{BREAST CANCER IN AA WOMEN: IMPLICATIONS FOR SCREENING MAMMOGRAPHY RECOMMENDATIONS}

Race/ethnicity-associated differences in populationbased incidence of TNBC are also relevant to the

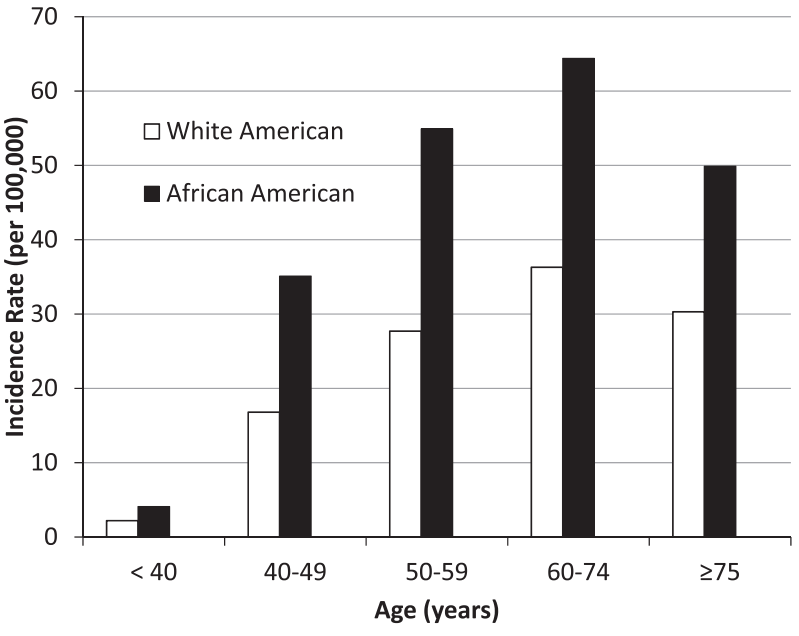

Figure 3. Population-based incidence rates of triple negative breast cancer stratified by age range at diagnosis, from California Cancer Registry (51).

controversial discussion of breast cancer surveillance and the age at which American women should initiate screening mammography. In November 2009 (25) the United States Preventive Services Task Force (USPSTF) published a reevaluation of the historic prospective randomized clinical trials conducted 20-30 years ago, comparing screening mammography to "usual medical care." As a result of this reevaluation, the USPSTF recommended that American women initiate screening mammography at age 50 years rather than 40 . They neglected to comment on the potential impact of delayed screening on AA women, who face an increased risk of TNBC as well as an increased risk of early-onset disease. As shown by Amirikia et al. (Fig. 3) in a study from the California Cancer Registry (26), population-based incidence rates of TNBC for AA women in the 40-49 year age range is comparable to those of WA women in the 60-69 year age range.

\section{TNBC IN WOMEN WITH AFRICAN ANCESTRY: IMPLICATIONS FOR GENETIC COUNSELING/ TESTING}

Triple negative breast cancer is known to be a marker of hereditary breast cancer susceptibility syndromes, such as BRCA1 mutations. In the early years of BRCA gene sequencing, little was known about frequency of BRCA mutations among AA pedigrees featuring strong family histories of breast and/or ovarian cancer. In light of correlations between TNBC and AA identity, more AA families are undergoing genetic counseling and testing, revealing that BRCA mutations 
Table 2. Frequency of BRCA Mutations in AA and Bahamian Breast Cancer Patients

\begin{tabular}{lc} 
Study, year & $\begin{array}{c}\text { Proportion of patients with BRCA mutation } \\
\text { (study population) }\end{array}$ \\
\hline Akbari et al. 2014 (28) & $\begin{array}{c}27 \% \text { (58/214 Bahamian patients unselected } \\
\text { for age or family history) }\end{array}$ \\
Sharma et al. $2014(65)$ & $7 \%$ (2/30 TNBC patients) \\
Greenup et al. 2013 (66) & $20 \%$ (17/83 TNBC patients) \\
Pal et al. 2013 (67) & $41 \%$ pathogenic; 35\% VUS (3/46 pathogenic \\
& variants; $16 / 46$ VUS) \\
Donenberg et al. 2011 (27) & $23 \%$ (49/214 Bahamian patients unselected \\
& for age or family history) \\
Nanda et al. 2005 (68) & $28 \%$ pathogenic; $44 \%$ VUS (7/43 high-risk \\
& families with pathogenic BRCA1 mutation; \\
& $5 / 43$ high-risk families with pathogenic \\
BRCA2 mutation; and 19/43 high-risk & families with VUS) \\
Gao et al. 2000 (69) & $18 \%$ (5/28 oncology clinic patients) \\
Gao et al. 1997 (70) & $56 \%$ (5/9 high-risk patients with BRCA1 \\
& mutation)
\end{tabular}

TNBC, triple negative breast cancer; VUS, variant of unknown significance.

are more common than previously thought. Table 2 summarizes the results of studies that have evaluated frequency of BRCA mutations in AA. Hurley $(27,28)$ identified a BRCA1 founder mutation unique to Caribbean women with African ancestry, based upon genetic testing in a series of patients from the Bahamas. It is furthermore plausible that low- and moderate-risk genetic variants exist that collectively contribute to the breast cancer burden of selected population subsets $(29,30)$.

Despite the notably high frequency of TNBC in sub-Saharan Africa, little is known about prevalence of BRCA mutations in this part of the continent. International patterns of BRCA1 and BRCA2 mutations were recently and comprehensively reviewed by Karami and Mehdipour (31). Most of the data regarding BRCA mutations in Africa are based upon northern African populations, with only one study each representing Nigeria and South Africa.

\section{TNBC IN WOMEN WITH AFRICAN ANCESTRY: RESEARCH IMPLICATIONS}

Figure 4 summarizes the results of existing data regarding the features of breast cancer as it afflicts AA, WA, and sub-Saharan African women. With regard to average age at diagnosis, frequency of adverse tumor features, and frequency of male breast cancer, a consistent pattern is seen with AA women always intermediate in extent of these features. This pattern suggests that extent of African ancestry is

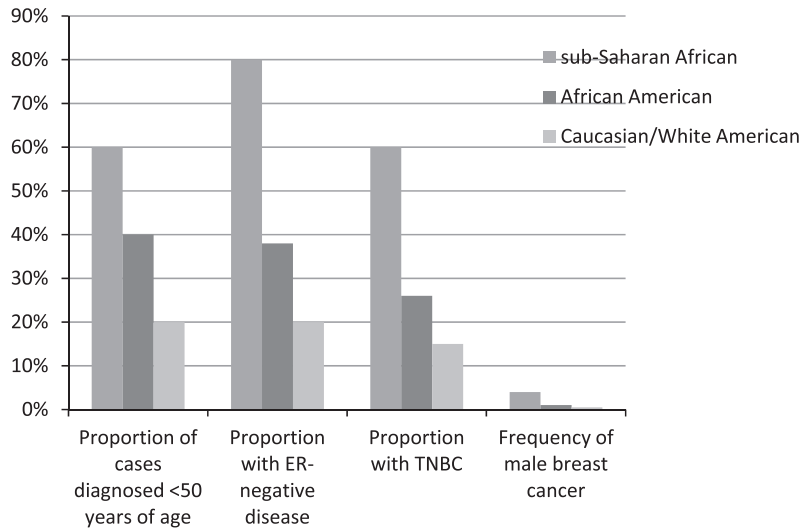

Figure 4. Frequency of breast cancer patterns in AA, Caucasian/ White Americans, and African populations $(3,52,53)$.

indeed associated with likelihood of expressing certain patterns of breast cancer, and this theory is hypothesis-generating for a variety of research studies investigating the pathogenesis of TNBC.

Fejerman et al. (32) performed admixture scans in nearly 1,500 AA breast cancer patients and confirmed that extent of African ancestry was associated with risk of hormone receptor-negative disease, but no specific ancestral marker predicting susceptibility for disease was identified. More recently, several genotyping analyses from the Black Women's Health Study have identified SNPs and patterns associated with African ancestry that are also correlated with risk of TNBC (33-35).

Breast cancer studies from the University of Michigan-Ghana breast cancer partnership have also identified novel patterns of molecular marker expression associated with mammary stem cells in sub-Saharan African populations. The mammary stem cell marker ALDH1 was found to be elevated in Ghanaian benign as well as malignant breast specimens (36), and the marker EZH2 was also found to have unique patterns in Ghanaian breast tissue compared to WA breast cancer patients (37).

Advances in gene expression studies are now demonstrating that TNBC is a heterogeneous breast cancer subset, characterized by distinct subtypes featuring tumor progression through specific pathways. The Vanderbilt group $(38,39)$ identified at least six different TNBC subtypes: two basal-like; one immunomodulatory; one mesenchymal; one mesenchymal stem cell-like; and one luminal androgen receptor). These subtypes are associated differential response to neo-adjuvant chemotherapy $(40,41)$ and may serve as a basis for targeted antiandrogen therapy with 
bicalutamide (42-46) for the luminal androgen receptor-positive TNBC. Preliminary data suggest novel patterns of androgen receptor expression in Ghanaian women (47) and additional research is necessary in the study of TNBC subtypes among women with African ancestry.

\section{SUMMARY}

The study of breast cancer in women with African ancestry has opened the door to unique research opportunities regarding subtypes and the genetics of this disease. International research efforts can advance our understanding of the pathogenesis of TNBC as well as hereditary susceptibility for breast cancer.

\section{REFERENCES}

1. Newman L, Fregene A. Breast cancer in African American women and women from sub-Saharan Africa. Cancer 2005; 103:1540-50.

2. Surveillance, Epidemiology and End Results Program Fast Stats. Availbale at: http://seer.cancer.gov/faststats/selections (accessed September 25, 2014).

3. Newman LA. Breast cancer disparities: high-risk breast cancer and African ancestry. Surg Oncol Clin N Am 2014;23:579-92.

4. Globocan. Globocan 2000: Cancer Incidence, Mortality and Prevalence Worldwide. [Internet website]. 2001; Version 1.0. 2003. Available at: http://www-dep.iarc.fr/cgi-bin/exe/globosx1.exe?dtype $=0$ select $=0\{00 \mathrm{AMP} 00\}$ value $=11\{00 \mathrm{AMP} 00\}$ sex $=1$ (accessed Febru ary 21,2003 ).

5. Stark A, Kleer CG, Martin I. African ancestry and higher prevalence of triple-negative breast cancer: findings from an international study. Cancer 2010;116:4926-32.

6. Ries L, Eisner M, Kosary C. SEER Cancer Statistics Review, 1975-2002. 2005. Available at: http://seer.cancer.gov/csr/ 1975_2002/ (accessed March 9, 2006).

7. Shamliyan T, Wang SY, Virnig BA, Tuttle TM, Kane RL. Association between patient and tumor characteristics with clinical outcomes in women with ductal carcinoma in situ. $J$ Natl Cancer Inst Monogr 2010;2010:121-9.

8. Li CI, Malone KE, Saltzman BS, Daling JR. Risk of invasive breast carcinoma among women diagnosed with ductal carcinoma in situ and lobular carcinoma in situ, 1988-2001. Cancer 2006;106:2104-12.

9. Innos K, Horn-Ross PL. Risk of second primary breast cancers among women with ductal carcinoma in situ of the breast. Breast Cancer Res Treat 2008;111:531-40.

10. Collins LC, Achacoso N, Haque R. Risk factors for noninvasive and invasive local recurrence in patients with ductal carcinoma in situ. Breast Cancer Res Treat 2013;139:453-60.

11. Bailes AA, Kuerer HM, Lari SA, Jones LA, Brewster AM. Impact of race and ethnicity on features and outcome of ductal carcinoma in situ of the breast. Cancer 2013;119:150-7.

12. Roses RE, Arun BK, Lari SA. Ductal carcinoma-in-situ of the breast with subsequent distant metastasis and death. Ann Surg Oncol 2011;18:2873-8.

13. Stark A, Stapp R, Raghunathan A. Disease-free probability after the first primary ductal carcinoma in situ of the breast: a comparison between African-American and White-American women. Breast Cancer Res Treat 2012;131:561-70.

14. Pal SK, Childs BH, Pegram M. Triple negative breast cancer: unmet medical needs. Breast Cancer Res Treat 2011;125:627-36.

15. Foulkes WD, Smith IE, Reis-Filho JS. Triple-negative breast cancer. N Engl J Med 2010;363:1938-48.

16. Alluri P, Newman LA. Basal-like and triple-negative breast cancers: searching for positives among many negatives. Surg Oncol Clin N Am 2014;23:567-77.

17. Perou CM. Molecular stratification of triple-negative breast cancers. Oncologist 2011;16(Suppl 1):61-70.

18. Chavez-Macgregor M, Clarke CA, Lichtensztajn D, Hortobagyi GN, Giordano SH. Male breast cancer according to tumor subtype and race: a population-based study. Cancer 2013;119:1611-7.

19. Millikan RC, Newman B, Tse CK. Epidemiology of basal-like breast cancer. Breast Cancer Res Treat 2008;109:123-39.

20. Ma H, Wang Y, Sullivan-Halley J. Use of four biomarkers to evaluate the risk of breast cancer subtypes in the women's contraceptive and reproductive experiences study. Cancer Res 2010;70:575-87.

21. Shinde SS, Forman MR, Kuerer HM. Higher parity and shorter breastfeeding duration: association with triple-negative phenotype of breast cancer. Cancer 2010;116:4933-43.

22. Phipps AI, Buist DS, Malone KE. Reproductive history and risk of three breast cancer subtypes defined by three biomarkers. Cancer Causes Control 2011;22:399-405.

23. Yang XR, Chang-Claude J, Goode EL. Associations of breast cancer risk factors with tumor subtypes: a pooled analysis from the Breast Cancer Association Consortium studies. J Natl Cancer Inst 2011;103:250-63.

24. Phipps AI, Chlebowski RT, Prentice R. Reproductive history and oral contraceptive use in relation to risk of triple-negative breast cancer. J Natl Cancer Inst 2011;103:470-7.

25. Nelson HD, Tyne K, Naik A, Bougatsos C, Chan BK, Humphrey L. Screening for breast cancer: an update for the U.S. Preventive Services Task Force. Ann Intern Med 2009;151:727-37, W237742.

26. Amirikia KC, Mills P, Bush J, Newman LA. Higher population-based incidence rates of triple-negative breast cancer among young african-american women: implications for breast cancer screening recommendations. Cancer 2011;117:2747-53.

27. Donenberg T, Lunn J, Curling D. A high prevalence of BRCA1 mutations among breast cancer patients from the Bahamas. Breast Cancer Res Treat 2011;125:591-6.

28. Akbari MR, Donenberg T, Lunn J. The spectrum of BRCA1 and BRCA2 mutations in breast cancer patients in the Bahamas. Clin Genet 2014;85:64-7.

29. Antoniou AC, Pharoah PD, McMullan G, Day NE, Ponder BA, Easton D. Evidence for further breast cancer susceptibility genes in addition to BRCA1 and BRCA2 in a population-based study. Genet Epidemiol 2001;21:1-18.

30. Gilliland FD. Ethnic differences in cancer incidence: a marker for inherited susceptibility? Environ Health Perspect 1997;105 (Suppl 4):897-900.

31. Karami F, Mehdipour P. A comprehensive focus on global spectrum of BRCA1 and BRCA2 mutations in breast cancer. BioMed Research International 2013;2013:928562.

32. Fejerman L, Haiman CA, Reich D. An admixture scan in 1,484 African American women with breast cancer. Cancer Epidemiol Biomarkers Prev 2009;18:3110-7.

33. Ruiz-Narvaez EA, Rosenberg L, Yao S. Fine-mapping of the 6q25 locus identifies a novel SNP associated with breast cancer risk in African-American women. Carcinogenesis 2013;34:287-91. 
34. Rosenberg L, Boggs DA, Bethea TN, Wise LA, AdamsCampbell LL, Palmer JR. A prospective study of smoking and breast cancer risk among African-American women. Cancer Causes Control 2013;24:2207-15.

35. Palmer JR, Ruiz-Narvaez EA, Rotimi CN. Genetic susceptibility loci for subtypes of breast cancer in an African American population. Cancer Epidemiol Biomarkers Prev 2013;22:127-34.

36. Schwartz T, Stark A, Pang J. Expression of aldehyde dehydrogenase 1 as a marker of mammary stem cells in benign and malignant breast lesions of Ghanaian women. Cancer 2013;119:488-94.

37. Pang J, Toy KA, Griffith KA. Invasive breast carcinomas in Ghana: high frequency of high grade, basal-like histology and high EZH2 expression. Breast Cancer Res Treat 2012;135:59-66.

38. Lehmann BD, Bauer JA, Chen X. Identification of human triple-negative breast cancer subtypes and preclinical models for selection of targeted therapies. J Clin Invest 2011;121:2750-67.

39. Chen X, Li J, Gray WH. TNBCtype: a subtyping tool for triple-negative breast cancer. Cancer informatics 2012;11:147-56.

40. Yu KD, Zhu R, Zhan M. Identification of prognosis-relevant subgroups in patients with chemoresistant triple-negative breast cancer. Clin Cancer Res 2013;19:2723-33.

41. Masuda H, Baggerly KA, Wang Y. Differential response to neoadjuvant chemotherapy among 7 triple-negative breast cancer molecular subtypes. Clin Cancer Res 2013;19:5533-40.

42. McGhan LJ, McCullough AE, Protheroe CA. Androgen receptor-positive triple negative breast cancer: a unique breast cancer subtype. Ann Surg Oncol 2013;21:361-7.

43. Thike AA, Yong-Zheng Chong L, Cheok PY. Loss of androgen receptor expression predicts early recurrence in triple-negative and basal-like breast cancer. Mod Pathol 2014;27:352-60.

44. Shah PD, Gucalp A, Traina TA. The role of the androgen receptor in triple-negative breast cancer. Womens Health (Lond Engl) 2013;9:351-60.

45. Mrklic I, Pogorelic Z, Capkun V, Tomic S. Expression of androgen receptors in triple negative breast carcinomas. Acta Histochem 2013;115:344-8.

46. McNamara KM, Yoda T, Takagi K, Miki Y, Suzuki T, Sasano H. Androgen receptor in triple negative breast cancer. J Steroid Biochem Mol Biol 2013;133:66-76.

47. Proctor E, Jiagge E, Kleer C. Androgen receptor expression in Ghanaian breast cancer cases: novel correlation with ALDH1 in triple-negative tumors. Paper presented at: Society of Surgical Oncology Annual Cancer Symposium 2014; Phoenix, AZ.

48. Surveillance, Epidemiology, and End Results program. Cancer Fast Stats. 2014. Available at: http://seer.cancer.gov/faststats/ selections.php? (accessed February 26, 2014).

49. Jemal A, Bray F, Center MM, Ferlay J, Ward E, Forman D. Global cancer statistics. CA Cancer J Clin 2011;61:69-90.

50. Jaeger BA, Jueckstock J, Andergassen U. Evaluation of two different analytical methods for circulating tumor cell detection in peripheral blood of patients with primary breast cancer. BioMed research international 2014;2014:491459.

51. Amirikia KC, Mills P, Bush J, Newman LA. Higher population-based incidence rates of triple-negative breast cancer among young African-American women: implications for breast cancer screening recommendations. Cancer 2011;117:2747-53.

52. Fregene A, Newman LA. Breast cancer in sub-Saharan Africa: how does it relate to breast cancer in African-American women? Cancer 2005;103:1540-50.

53. Newman LA. Breast cancer in African-American women. Oncologist 2005;10:1-14.
54. Trinkaus ME, Sayed S, Gakinya SM, Moloo Z, Hanna W, Rahim Y. Triple negative and basal-like breast cancer in East Africa. Breast J 2011;17:438-40.

55. Roy I, Othieno E. Breast carcinoma in Uganda: microscopic study and receptor profile of 45 cases. Arch Pathol Lab Med 2011;135:194-9.

56. Bird PA, Hill AG, Houssami N. Poor hormone receptor expression in East African breast cancer: evidence of a biologically different disease? Ann Surg Oncol 2008;15:1983-8.

57. Dent R, Trudeau M, Pritchard KI. Triple-negative breast cancer: clinical features and patterns of recurrence. Clin Cancer Res 2007;13(15 Pt 1):4429-34.

58. Turkoz FP, Solak M, Petekkaya I. Association between common risk factors and molecular subtypes in breast cancer patients. Breast 2013;22:344-50.

59. Fostira F, Tsitlaidou M, Papadimitriou C. Prevalence of BRCA1 mutations among 403 women with triple-negative breast cancer: implications for genetic screening selection criteria: a Hellenic Cooperative Oncology Group Study. Breast Cancer Res Treat 2012;134:353-62.

60. Song Q, Huang R, Li J. The diverse distribution of risk factors between breast cancer subtypes of ER, PR and HER2: a 10-year retrospective multi-center study in China. PLOS ONE 2013;8: e72175.

61. Carey LA, Perou CM, Livasy CA. Race, breast cancer subtypes, and survival in the Carolina Breast Cancer Study. JAMA 2006;295:2492-502.

62. Morris GJ, Naidu S, Topham AK. Differences in breast carcinoma characteristics in newly diagnosed African-American and Caucasian patients: a single-institution compilation compared with the National Cancer Institute's Surveillance, Epidemiology, and End Results database. Cancer 2007;110:876-84.

63. Lund MJ, Trivers KF, Porter PL. Race and triple negative threats to breast cancer survival: a population-based study in Atlanta, GA. Breast Cancer Res Treat 2009;113:357-70.

64. Moran MS, Yang Q, Harris LN, Jones B, Tuck DP, Haffty BG. Long-term outcomes and clinicopathologic differences of African-American versus white patients treated with breast conservation therapy for early-stage breast cancer. Cancer 2008;113:2565-74.

65. Sharma P, Klemp JR, Kimler BF. Germline BRCA mutation evaluation in a prospective triple-negative breast cancer registry: implications for hereditary breast and/or ovarian cancer syndrome testing. Breast Cancer Res Treat 2014;145:707-14.

66. Greenup R, Buchanan A, Lorizio W. Prevalence of BRCA mutations among women with triple-negative breast cancer (TNBC) in a genetic counseling cohort. Ann Surg Oncol 2013;20:3254-8.

67. Pal T, Bonner D, Kim J. Early onset breast cancer in a registry-based sample of African-american women: BRCA mutation prevalence, and other personal and system-level clinical characteristics. Breast J 2013;19:189-92.

68. Nanda R, Schumm LP, Cummings S. Genetic testing in an ethnically diverse cohort of high-risk women: a comparative analysis of BRCA1 and BRCA2 mutations in American families of European and African ancestry. JAMA 2005;294:1925-33.

69. Gao Q, Tomlinson G, Das S. Prevalence of BRCA1 and BRCA2 mutations among clinic-based African American families with breast cancer. Hum Genet 2000;107:186-91.

70. Gao Q, Neuhausen S, Cummings S, Luce M, Olopade OI. Recurrent germ-line BRCA1 mutations in extended African American families with early-onset breast cancer. Am J Hum Genet 1997;60:1233-6. 